\title{
The Strategic Role of Dividends and Debt in Markets with Imperfect Competition
}

\author{
Engelbert J. Dockner ${ }^{1}$ • Helmut Elsinger ${ }^{2}$. \\ Andrea Gaunersdorfer ${ }^{3}$ (D)
}

Published online: 3 March 2018

(C) The Author(s) 2018. This article is an open access publication

\begin{abstract}
In a seminal paper Brander and Lewis (Am Econ Rev 76:956-970, 1986) show that oligopolistic firms with limited liability follow a more aggressive output strategy as their leverage increases. In a follow-up paper Glazer (J Econ Theory 62:428-443, 1994) points out that when debt is long term and rival firms choose their equilibrium quantities in two consecutive periods, they have an incentive to be more collusive in the first period than static oligopolists would be. In this paper we argue that the incentive to collude is driven by limited liability and the dividend policy of the firm. We find that increasing leverage causes firms in both periods to increase their output and hence to be more aggressive. Additionally, we find that it is always optimal to pay out profits immediately. Moreover, we show that the symmetric game admits multiple equilibria some of which cause firms to choose asymmetric product market strategies.
\end{abstract}

Keywords Financial and product market interactions - Cournot competition · Debt · Payout policy $\cdot$ Multiple equilibria

\section{Introduction}

Beginning with the seminal paper of Brander and Lewis [3] a whole strand of the literature has shown that there are important linkages between financial structure and product market

Engelbert J. Dockner-deceased.

The views expressed are not necessarily those of the OeNB.

Andrea Gaunersdorfer

andrea.gaunersdorfer@univie.ac.at

1 Department of Finance, Vienna University of Economics and Business, 1020 Vienna, Austria

2 Oesterreichische Nationalbank, Otto-Wagner-Platz 3, 1090 Vienna, Austria

3 Department of Finance, University of Vienna, Oskar-Morgenstern-Platz 1, 1090 Vienna, Austria 
strategies. ${ }^{1}$ Brander and Lewis adopt the view that managers generally have incentives to maximize the equity value of the firm. In this setting leverage changes the payoffs to equity and therefore affects the product market strategy. In particular, Brander and Lewis show that if product markets are characterized by oligopolistic competition, more leverage causes the firms to be more aggressive (i.e., produce more) in the output market. Oligopolists will tend to have more debt than monopolists or firms in competitive industries. Maksimovic [14] further extends the model by analyzing the effect of a firm's capital structure on its product market strategy in the context of a model of repeated oligopoly. He shows that high levels of debt deters equity holders to deviate from collusive behavior in the product market.

The intuition of Brander and Lewis is straightforward and is a consequence of limited liability and the manager's incentive to maximize equity value. To see how debt influences product market strategies in this framework let us consider their model in more detail. Assume that there are two Cournot oligopolists that face uncertain demand, where demand, and hence marginal revenue, increases in good states. Firms play a two-stage game in which debt levels are determined in the first period and equilibrium outputs are chosen in the second. Optimal product market behavior requires that if marginal revenue is high, firms will set high levels of quantity. Since firms set their quantities before demand realizations are known, as a consequence of limited liability they ignore those states where demand is low and hence they have an incentive to be more aggressive in the output market. Consequently, increasing debt causes the firms to be even more aggressive and further increase output, i.e., pursue riskier product strategies. ${ }^{2}$ In a Cournot market this mechanism causes firms to commit to higher output levels since the optimal response of the rival is then to produce less, thereby making the opponent better off. Hence, in this model debt serves as a commitment device for more aggressive output market strategies.

After showing how output depends on debt they investigate whether there is an optimal level of debt. For the case that marginal revenue increases with the level of good states of the world they get the result that debt levels will be strictly positive.

Showalter [19] raises the question whether the results of Brander and Lewis depend on the assumption of Cournot competition. He shows in a critical note that the optimal strategic debt choice of Bertrand competitors depends on the type of uncertainty that exists in the output market. He proves that for cost uncertainty prices have to fall when debt rises. If demand is uncertain increasing debt will increase prices. Hence, cost uncertainty will make competitors more aggressive with increasing debt level, whereas demand uncertainty will weaken the competition with increasing debt levels. Moreover, he derives that under cost uncertainty firms will hold no debt in equilibrium. If demand is uncertain, firms will choose a positive debt level in equilibrium. ${ }^{3}$

Pichler et al. [18] identify two effects of leverage on prices. Owners of a firm have incentives to increase the firm's market share in order to engage in risk shifting where the timing of this risk shifting is determined by the firm's debt maturity structure. They call this effect "dynamic limited liability" effect. On the other hand, the presence of default risk causes firms

\footnotetext{
${ }^{1}$ Harris and Raviv [13] survey capital structure theories until the beginning of the 1990s based on agency costs, asymmetric information, product/input market interactions, and corporate control considerations (but excluding tax-based theories). A later review on the relationship between financing decisions and product market behavior is Maksimovic [15]. Parsons and Titman [16] review empirical studies that examine how a firms financing choice affects its strategic decisions and relationships with its nonfinancial stakeholders.

2 Dimitrov [7] provides a summary of theoretical arguments through which financial leverage can affect the operating risk of a firm and discusses empirical evidence.

3 Other papers that analyze price competition in a framework similar to Brander and Lewis are $[1,6,20]$. Chevalier [5] empirically studies the effect that debt has on the pricing policy of a firm.
} 
to underinvest in positive net present value projects because its owners discount at a higher rate than if there is no default risk. Therefore, higher default probability leads owners to invest less in market share and to set higher prices. Thus, a firm's pricing policy depends on its financial structure both through the probability with which the firm defaults and through the way in which the default probability varies over time. These effects are nonlinear and their interaction is positive for some firm-years and negative for others. Using a sample of hotels in Austrian ski resorts which are exposed to demand uncertainty due to uncertainty about snow conditions, they provide empirical evidence for these two effects.

Fulghieri and Nagarajan [10] show that debt holders and equity holders in the Brander and Lewis framework would be better off if the firms repurchased their debt just prior to the quantity decision. Their result hinges on the assumption that each firm's output decision has to be made before the amount of the competitors's debt, which is repurchased by the competitor, is observed. Therefore, they show that firms will hold no debt whatsoever if they have the opportunity to disguise their leverage. Furthermore, they show that under asymmetric information there exist lasting debt contracts which preserve the commitment value and in which not all debt is renegotiated away.

Faure-Grimaud [8] changes the framework of Brander and Lewis by assuming that the lenders cannot verify the demand realization. Under this assumption he derives the result that lenders offer an optimal renegotiation-proof financial contract which resembles a standard debt contract. Contrary to Fulghieri and Nagarajan [10] he assumes that the borrowed amount is common knowledge. As the lender does not observe the true state of nature, there has to be an incentive scheme to make the borrower report truthfully. This is done via rewards that depend on the reported state similar to Bolton and Scharfstein [2]. Not getting this reward can be interpreted as bankruptcy costs. Faure-Grimaud derives the result that the equilibrium output for indebted firms is lower than the equilibrium output level without debt. The intuition is that higher output certainly increases the payoff to equity holders in the states where they are residual claimants but is more than offset by a higher reimbursement, which is necessary to keep the debt contract incentive compatible, and a lower probability to be rewarded. The debt contract in Faure-Grimaud's paper basically forces the manager to maximize debt and equity value simultaneously instead of equity value alone.

Campello [4] proposes that debt can boost and hurt performance of a firm. If there are information asymmetries between the parties of a financial contract, firms with greater access to external financing can threaten their rivals with debt financed product market overinvestment. Thus, debt can initially provide for a product market advantage for those firms. If, however, parties can renegotiate contracts, debt issuance cannot support aggressive market strategies beyond a certain threshold. Campello provides a simple model which implies a nonmonotonic association between firm debt and product market outcomes, building on similar sets of assumptions as Faure-Grimaud [8]. He empirically examines the relation between firm relative to rival debt and sales performance using data from a panel of 115 well-defined product markets over three decades. His findings suggest that moderate debt levels may, on the margin, yield market share gains. Beyond a threshold, however, additional indebtedness leads to significant sales underperformance.

While the theory initiated by Brander and Lewis emphasizes the linkages between the product and financial markets, Glazer [11] challenges their prediction that debt always results in more aggressive output market behavior. In particular, he considers the case in which firms face a two-period Cournot game where they choose output in each period, while debt is long term and is fully repaid only at the end of the second period when the demand uncertainty is resolved. In this setting of long-term debt, firms are not allowed to pay out dividends at the end of the first period. Under these assumptions Glazer [11] shows that the higher the firms' 
profits in the first period, the less aggressive their product market behavior in the subsequent period. This observation leads Glazer to the conclusion that by issuing long-term debt (debt that cannot be repaid at the end of the first period) rival firms may induce collusive behavior. ${ }^{4}$

Glazer's result is confirmed by an empirical study of Phillips [17] for three industries (the fiberglass, tractor trailer, and polyethylene). He finds evidence that market share changes following increases in financial leverage. Firms that increase their financial leverage either lose market share or fail to gain market share when smaller rivals exit the industry. In these industries, rival firms have high financial leverage, and entry is relatively difficult. In the gypsum industry, however, firm-level data show that the largest firms increased their market share at the expense of small firms and operating margins decrease which is consistent with the model of Brander and Lewis [3] and Maksimovic [14]. Phillips emphasizes that the gypsum industry is different in several ways from the other three industries. Several major competitors did not increase their leverage, and barriers to entry are low because the production technology is simple with small plant sizes relative to the size of the market.

Smith et al. [21] test hypotheses which are opposite to the theory of Glazer [11] for publicly listed firms of New Zealand in the period from 1984 to 2008. Before that period reforms in the New Zealand economy occurred which generated a more competitive environment. They find that when publicly listed New Zealand companies use leverage, there is an increase in relative-to-industry sales growth, but a decrease in relative-to-industry return on assets. They interpret these findings as evidence that New Zealand firms use more long-term debt to compete aggressively against their rivals and to increase their market share. On the other hand, they find no evidence that performance has an impact on leverage. Thus, when sales growth has been achieved, New Zealand firms appear to maintain their levels of long-term debt, rather than reduce them. The reason for this may be to ensure their sales growth continues in the future.

Hadlock and Sonti [12] provide evidence that increases in fixed liabilities arising from asbestos litigation (which are debt-like claims in that they are senior to equity in the event of default) lead to more aggressive product market interactions. They argue that a deviation from collusive behavior may result in high current cash flows that could be immediately paid out to equity holders if the fixed claims are not immediately due and there are few contractual restrictions on cash distributions to equity holders. Thus, a firm with an upward shock to its fixed liabilities could rationally prefer to take an aggressive current action, as the future expense of this action is borne primarily by the firms fixed claimants and competitors.

In this paper, we deal with Glazer's analysis and point out that his prediction that longterm debt causes firms to be more collusive in the initial periods of the planning horizon does not hold which is in line with Smith et al. [21] and Hadlock and Sonti [12]. In particular, we prove that issuing debt (even if it is long term) always causes firms to be more aggressive in the product market. Moreover, we find that the difference from the result found by Glazer [11] is a consequence of how frequently profits are paid out as dividends to shareholders. Hence, the results are driven by the fact that there is a dynamic link between the two periods. When profits in the first period are retained, they influence the bankruptcy states in the second period.

To see what kind of economic mechanism causes our results let us refer to Glazer [11]. He looks at the following two scenarios. In the first, firms produce over two periods and issue an amount of debt that exceeds profits generated in the first period. Since managers maximize equity value, higher residual debt from the first period (i.e., that amount of debt that is carried

4 It is important to point out that while Brander and Lewis [3] present a theory of optimal capital structure, Glazer [11] only analyzes the effects of debt on product market behavior. 
over into the second period) induces firms to be more aggressive in the second period and consequently have lower profits. This corresponds to the Brander and Lewis effect of debt. As a consequence, if firms produce over two periods, they have an incentive to carry over as little residual debt as possible into the second period; hence, they restrict output in the first. The case of long-term debt can be viewed alternatively as one in which profits in the form of dividends are fully paid out only after uncertainty is resolved, i.e., at the end of the second period. This implies that Glazer's model can also be seen as one in which production decisions occur more frequently than dividend payments.

The first scenario with debt financed firms is now compared to the second scenario in which firms are fully equity financed. In this case, however, Glazer assumes that profits are paid out to shareholders in every period, a scenario that is not compatible with the case of long-term debt. If firms, on the contrary, do not fully pay out profits as dividends, they can survive some of the bad states of demand in the next period which would have caused financial distress otherwise. Hence, the number of good states increases, which results in less aggressive behavior than the case where dividends are paid out every period. Limited liability, however, still causes firms to be more aggressive than static Cournot. Therefore, the firms have the same incentive to collude as described above.

To summarize, our paper makes the point that it is the limited liability effect together with the dynamic link of retained profits ${ }^{5}$ that drives the result of Glazer and not long-term versus short-term debt. In particular, we prove that in the case where the sequence of dividend payments does not coincide with the sequence of production decisions equilibrium, output decisions in both periods are increasing with the level of debt independent of whether debt is long or short term. Therefore, contrary to Glazer, long-term debt does not cause prices to fluctuate more.

All these results relate to the effects of debt on product market behavior. Additionally we show by means of a numerical example that the dynamic symmetric game admits asymmetric subgame-perfect equilibria. This observation leads us to conclude that firms which face similar demand characteristics and financial structure may very well end up with very different output market strategies.

Our paper is organized as follows. In the next section we present the model which is identical to that of [11]. In Sect. 3 we derive our main results and present some numerical examples, and finally Sect. 4 concludes the paper.

\section{The Model}

The specification of our model follows that of Glazer [11]; hence, its description can be brief. We consider a duopoly market in which firms produce a homogeneous product over two periods. The quantity produced by firm $i$ in period 1 is denoted by $x_{i}$. Industry output in the first period $X=x_{1}+x_{2}$ is related to the market price, $P^{1}$, by means of an inverse demand function which in its linear form is given by ${ }^{6}$

\footnotetext{
5 In our model retained profits play the role of negative debt. This neglects the fact that when external finance is costly, cash should not be considered as the opposite of debt. Frésard [9] empirically studies how cash holdings affect a firm and its rivals' competitive behavior. He provides evidence that cash policy comprises a substantial product market dimension and that cash and debt policy have distinct implications for product market conducts.

6 The general conclusions of our paper do not depend on the functional form of the demand and cost functions. The linearity assumption substantially reduces the complexity of the problem, however.
} 


$$
P^{1}=a+\frac{1}{2}-X
$$

where $a>0$. Marginal production costs are assumed to be constant, i.e., costs are given by $C\left(x_{i}\right)=a x_{i}$. Hence, the first period profit function becomes

$$
\Pi_{i}^{1}=\left(a+\frac{1}{2}-x_{i}-x_{j}\right) x_{i}-a x_{i}=\left(\frac{1}{2}-x_{i}-x_{j}\right) x_{i} .
$$

In the second period each firm chooses a quantity denoted by $y_{i}$ under the assumption of uncertain demand. Hence, the inverse demand function becomes

$$
P^{2}=a+z-y_{i}-y_{j},
$$

where $P^{2}$ is the price in period 2 and $z$ is a random variable that is uniformly distributed over the interval $[0,1]$. Hence, on average, demand in period 2 is equal to that in period 1 , but it can deviate from it. The cost structure in period 2 is assumed to be identical to that in period 1.

Profits of firm $i$ in period 2 now depend not only on the quantities produced but also on random demand, represented by $z$. For a given realization of $\bar{z}$ profits are given by

$$
\Pi_{i}^{2}=\left(\bar{z}-y_{i}-y_{j}\right) y_{i} .
$$

With given first and second period quantities expected profits of firm $i$ with unlimited liability become

$$
\Pi_{i}=\Pi_{i}^{1}+\int_{0}^{1}\left(z-y_{i}-y_{j}\right) y_{i} \mathrm{~d} F(z)
$$

with distribution function $F(z)=z$. In case of no debt and no limited liability firms determine their optimal quantities on the basis of the present value of the expected profit which in the case of a zero interest rate is given by (3).

Introducing debt and limited liability changes the structure of the problem considerably. To see this, let us first look at the case of limited liability. Since demand in period two is stochastic, it is possible that the firm faces financial distress. In particular, since the production decisions are based on ex ante expectations of demand, it is possible that ex post realizations of $z$ are so low that the profits in period 2 are negative. Depending on whether or not profits from period 1 have been paid out as dividends the firm may face bankruptcy. In the case where the accumulated profits over both periods do not cover the payments to the variable factors of production (i.e., wages to workers and expenditures to suppliers for intermediate products or resources) the firm is bankrupt and the owners of the factors of production are in the same position as debt holders. Hence, in the case of limited liability they become the residual claimants. As a consequence the manager of the firm must take into account the case of bankruptcy when making equilibrium production decisions. If he is risk-neutral and maximizes the equity value of the firm over the two periods his objective function in case that there are no dividend payments at the end of period 1 becomes

$$
\begin{aligned}
V_{i} & =\int_{\hat{z}_{i}}^{1}\left(\Pi_{i}^{2}\left(z, y_{i}, y_{j}\right)+\Pi_{i}^{1}\left(x_{i}, x_{j}\right)\right) \mathrm{d} F(z) \\
& =\int_{\hat{z}_{i}}^{1} \Pi_{i}^{2}\left(z, y_{i}, y_{j}\right) \mathrm{d} F(z)+\Pi_{i}^{1}\left(x_{i}, x_{j}\right)\left(1-F\left(\hat{z}_{i}\right)\right) .
\end{aligned}
$$

where $1-F\left(\hat{z}_{i}\right)$ is the probability that the firm is not bankrupt and $\hat{z}_{i}$ is that level of demand realization for which profits that are earned in the first period (and which are not paid out as dividends) are sufficient to cover the operating losses from the second period, i.e., 


$$
\Pi_{i}^{2}\left(\hat{z}_{i}, y_{i}, y_{j}\right)+\Pi_{i}^{1}\left(x_{i}, x_{j}\right)=0 .
$$

Clearly, in this case the frequency of the production decisions does not coincide with that of the dividend payments. While production choices are made in the first and the second periods, dividends are only paid out after demand uncertainties are resolved at the end of the second period.

Things are different if managers pay out dividends with the same frequency as production decisions are made. In that case production decisions in the first period are made in the same way as in the static Cournot model (i.e., based on the profit function $\Pi_{i}^{1}$ ) and realized profits are distributed to shareholders. We assume that managers follow a dividend policy so that a fraction of first period profits equal to $1-\alpha_{i}\left(0 \leq \alpha_{i} \leq 1\right)$ is paid out as dividends. Quantity decisions in the second period are then made under the assumption that for some levels of $z$ bankruptcy occurs and that these levels do depend on the amount of dividends paid out at the end of period 1. This implies that the two-period objective function of a risk-neutral equity maximizing manager becomes

$$
\begin{aligned}
V_{i} & =\left(1-\alpha_{i}\right) \Pi_{i}^{1}\left(x_{i}, x_{j}\right)+\int_{\hat{z}_{i}}^{1}\left(\Pi_{i}^{2}\left(z, y_{i}, y_{j}\right)+\alpha_{i} \Pi_{i}^{1}\left(x_{i}, x_{j}\right)\right) \mathrm{d} F(z) \\
& =\left(1-\alpha_{i}\right)\left(\frac{1}{2}-x_{i}-x_{j}\right) x_{i}+\int_{\hat{z}_{i}}^{1}\left[\left(z-y_{i}-y_{j}\right) y_{i}+\alpha_{i}\left(\frac{1}{2}-x_{i}-x_{j}\right) x_{i}\right] \mathrm{d} F(z),
\end{aligned}
$$

where $\hat{z}_{i}$ is that level of demand for which profits of the second period together with that fraction of period 1 profits not paid out as dividends (i.e., retained earnings of the first period $\alpha_{i} \Pi_{i}^{1}$ ) are equal to zero, i.e.,

$$
\Pi_{i}^{2}\left(\hat{z}_{i}, y_{i}, y_{j}\right)+\alpha_{i} \Pi_{i}^{1}\left(x_{i}, x_{j}\right)=\left(\hat{z}_{i}-y_{i}-y_{j}\right) y_{i}+\alpha_{i}\left(\frac{1}{2}-x_{i}-x_{j}\right) x_{i}=0,
$$

We should note that in case of no dividend payments at the end of period $1\left(\alpha_{i}=1\right)$ the objective function (6) is identical to (4) and the bankruptcy constraint becomes (5).

Introducing dividend payments in the model of Glazer [11] provides us with two different opportunities of modeling dividend policy. We can assume that the firm's dividend policy is exogenously determined and look only on the influence of a predetermined level of dividend payments on the bankruptcy states and hence on the optimal production decisions. Alternatively we can allow managers to choose an equity value maximizing dividend policy and hence derive it endogenously. In this paper we will deal with both cases but start with the first one.

So far we have not introduced debt into our model. If firms issue debt $D_{i}$, which is partly paid back at the end of the first period, ${ }^{7}$ the problem of equity maximizing managers is given by

$$
\begin{aligned}
V_{i} & =\left(1-\alpha_{i}\right) \Pi_{i}^{1}\left(x_{i}, x_{j}\right)+\int_{\hat{z}_{i}}^{1}\left(\Pi_{i}^{2}\left(z, y_{i}, y_{j}\right)+\alpha_{i} \Pi_{i}^{1}\left(x_{i}, x_{j}\right)-D_{i}\right) \mathrm{d} F(z) \\
& =\left(1-\alpha_{i}\right) \Pi_{i}^{1}\left(x_{i}, x_{j}\right)+\int_{\hat{z}_{i}}^{1}\left(\Pi_{i}^{2}\left(z, y_{i}, y_{j}\right)+R_{i}\left(x_{i}, x_{j}, \alpha_{i}, D_{i}\right)\right) \mathrm{d} F(z),
\end{aligned}
$$

\footnotetext{
7 If firms retain the fraction $\alpha_{i} \Pi_{i}^{1}\left(x_{i}, x_{j}\right)$ of period 1 profits and use it to pay back debt at the end of the period, residual debt that is carried over to the second period is given by $D_{i}-\alpha_{i} \Pi_{i}^{1}\left(x_{i}, x_{j}\right)$.
} 
where for notational convenience we have introduced

$$
R_{i}\left(x_{i}, x_{j}, \alpha_{i}, D_{i}\right)=\alpha_{i} \Pi_{i}^{1}\left(x_{i}, x_{j}\right)-D_{i}
$$

and $\hat{z}_{i}$ is given by

$$
\Pi_{i}^{2}\left(\hat{z}_{i}, y_{i}, y_{j}\right)+R_{i}\left(x_{i}, x_{j}, \alpha_{i}, D_{i}\right)=\left(\hat{z}_{i}-y_{i}-y_{j}\right) y_{i}+\alpha_{i}\left(\frac{1}{2}-x_{i}-x_{j}\right) x_{i}-D_{i}=0 .
$$

$R_{i}\left(x_{i}, x_{j}, \alpha_{i}, D_{i}\right)$ corresponds to net retained first period profits. If this expression is negative, we call $\left|R_{i}\right|$ residual debt.

In the case where debt is long term (i.e., profits earned in the first period are not sufficient to repay debt entirely) and $\alpha_{i}=1$ problem (7) coincides from a shareholder point of view with the case where there are no dividend payments at the end of the first period. Therefore, when one wants to study the impact of long run debt on the product market strategy of a firm one must compare the outcome of model (7) with $\alpha_{i}=1$ to that of (4). This is not done in the paper by Glazer [11]. When he studies the impact of long run debt on the product market strategy he compares problem (7) with $\alpha_{i}=1$ to problem (6) with $\alpha_{i}=0$ (i.e., problem (4)). This implies that we have two different dividend policies at work. In the case of debt, managers pay out no dividends at the end of the first period, while in the case of no debt all first period profits are paid out as dividends. We will show that this difference is crucial for the impact of debt on the product market strategy.

\section{Dividend Payments and the Impact of Debt on the Product Market Strategy of a Firm}

Our aim in this section is to analyze the relationship between dividend payments, debt and product market behavior of oligopolistic firms. In particular, we point out that it is the way that dividends are paid out to shareholders that induces firms to more or less collusive behavior than static Cournot competitors. If firms pay out dividends in the first period, they influence the bankruptcy states and hence the product market strategy in the second period. In a twoperiod model the subgame-perfect equilibrium in the second period is characterized by a product market behavior that is more aggressive the lower the profits retained from the first period are. Since both the dividend and the debt policy of the firm influence the profits carried over to the second period, it is clear that the dividend and debt policy influence the product market strategy. Since more aggressive behavior causes both firms ex post to be worse off, they have an incentive to earn as much profits as possible in the first period. This implies collusive behavior. We will show that this incentive is a consequence of limited liability and equity value maximizing managers and is not necessarily dependent on the debt policy of the firm. It very much depends on the level of net retained earnings (residual debt) carried over into the second period. But we note that net retained earnings (residual debt) depend on the debt and the dividend policy. Hence, one or the other or both effects can cause the result. We will prove, however, that debt can have an influence on the output strategies in both periods. As in Brander and Lewis [3] debt will cause firms to produce more in both periods than they would otherwise do in a static Cournot model.

As a first step we review the impact of net retained earnings carried over into the second period on the output market strategy of a firm (see Brander and Lewis [3] and Glazer [11]). 
We assume that net retained profits are less than the profits of a Stackelberg leader in the static first period Cournot game and restrict the initial debt levels $D_{1}$ and $D_{2}$ to $1 / 16{ }^{8}$

Proposition 0 (a) For given first period quantities $\left(x_{i}, x_{j}\right)$ and corresponding profits $\Pi_{i}^{1}$ in the first period, second period quantities, $y_{i}^{e}$, that correspond to a subgame-perfect equilibrium will be lower the higher the firm's net retained earnings, i.e., $\frac{\mathrm{d} y_{i}^{e}}{\mathrm{~d} R_{i}}<0$. Quantities are increasing in the rival firm's net retained earnings in the first period, i.e., $\frac{\mathrm{d} y_{i}^{e}}{\mathrm{~d} R_{j}}>0$.

(b) The expected second period equilibrium equity value of firm $i, V_{i}^{2, e}$, will be higher the higher the own and the rival firm's net retained earnings, $0<\frac{\mathrm{d} V_{i}^{2, e}}{\mathrm{~d} R_{i}}<1-F\left(\hat{z}_{i}\right)<1$ and $\frac{\mathrm{d} V_{i}^{2, e}}{\mathrm{~d} R_{j}}>0$.

\section{Proof See "Appendix."}

The more aggressive output strategy of the firms in the second period reflects the fact that managers maximize the equity value of the firm and concentrate only on the good states of demand. Since lower net retained profits carried over to the second period causes $\hat{z}_{i}$ to increase, managers ignore a larger set of demand realizations and base their output decision only on higher values of $z$. Since marginal revenue in the second period is increasing in $z$, this causes them to be more aggressive than in a static Cournot market. In the case that the level of issued debt increases this even causes an increase in total expected equity value. ${ }^{9}$

After we have identified the impact of dividend payments (and debt) on the output market strategy in the second period we are interested in its effect on the first period quantities. In particular, we address the question if dividend policy cause the firms to be more collusive in the first period.

Lemma 1 First period quantities are characterized by the following.

1. Let $B^{i}\left(x_{j}\right)$ be the best response of player $i$ to a given quantity $x_{j}$ of player $j$ when both play a static Cournot game in the first period and let $x_{i}^{e}(\alpha, \alpha)=x_{j}^{e}(\alpha, \alpha)$ be the symmetric output in period 1. Then $x_{i}^{e}(\alpha, \alpha)<B^{i}\left(x_{j}^{e}(\alpha, \alpha)\right)$ for $\alpha \neq 0$.

2. $\frac{\partial \Pi_{i}^{1}}{\partial x_{i}}>0$ for $\alpha_{j} \neq 0$. Hence, firm $i$ produces less than Cournot output.

3. For $\alpha_{j}=0$ we obtain the Cournot solution for player $i$.

Proof See "Appendix."

Lemma 1 is an interesting result. It states that if firms can credibly announce a dividend policy, they have an incentive for collusive behavior. The economic intuition of this result is identical to that of Glazer [11]. But what is important here is that we identified net retained profits as the driving force behind collusive behavior.

As an immediate consequence of Proposition 0 and Lemma 1 we can compare equilibrium quantities with full and without dividend payments. We denote first and second period

\footnotetext{
8 These are rather weak and sensible assumptions. The Stackelberg profit would be the highest attainable profit in the first period, and a debt level of 1/16 corresponds to twice the Stackelberg profit. Higher debt levels would never be repaid.

9 It should be noted that Glazer [11] states that $\frac{\mathrm{d} V_{i}^{e}}{\mathrm{~d} D_{i}}$ can be either positive or negative. Since we study a more specified model we are able to show that the equity value of the firm always increases with the level of debt.
} 
equilibrium quantities in the case when all profits from the first period are distributed as dividends $\left(\alpha_{i}=0\right)$ by $x_{i}^{\text {div }}$, and $y_{i}^{\text {div }}$, respectively. When all profits are retained $\left(\alpha_{i}=1\right)$ we denote the corresponding quantities as $x_{i}^{\text {nodiv }}$ and $y_{i}^{\text {nodiv }}$, respectively.

Corollary 1 First period quantities in case when all first period profits are distributed to shareholders $\left(\alpha_{i}=0\right)$ are higher than quantities when profits are retained, i.e., $x_{i}^{\text {div }}>x_{i}^{\text {nodiv }}$. Second period quantities in the case of dividend payments $\left(\alpha_{i}=0\right)$ are higher than in the case of retained earnings, i.e., $y_{i}^{\mathrm{div}}>y_{i}^{\text {nodiv }}$.

The results of Corollary 1 state that in a strategic output market with limited liability dividend policy can critically influence the product market behavior of firms. In particular, dividend payments cause firms to be more aggressive in both periods.

This last result suggests that Glazer's finding on the influence of debt on the product market strategy of a firm critically depends on the assumption that in case of no debt all profits earned in period 1 are distributed to the shareholders. If, on the contrary, we assume that profits of period 1 are retained and compare an equilibrium with no debt to a situation with debt, we get the following result for our stylized model that we establish through numerical analysis.

Proposition 1 In a symmetric equilibrium in which first period profits are retained $\left(\alpha_{i}=1\right)$, issuing debt (either long or short term) causes firms to increase quantities in the first and in the second period, i.e., $\frac{\mathrm{d} x_{i}^{e}}{\mathrm{~d} D_{i}}>0$ and $\frac{\mathrm{d} y_{i}^{e}}{\mathrm{~d} D_{i}}>0$.

We show this result by solving the optimization problem numerically. Figure 1 shows the change in quantities corresponding to a symmetric change in the level of debt. This diagram shows that second period quantities are set more aggressively than first period ones. This is in line with the theoretical results of Brander and Lewis [3] and Glazer [11]. The economic interpretation for increasing quantities in the first period is as follows. Given first period outputs, increasing initial debt implies lower retained earnings and thus lower profits. To compensate for this loss each firm has the incentive to increase its first period profit by increasing output. This is possible because equilibrium output is lower than static Cournot output. Since we restrict our analysis to symmetric equilibria the same argument holds for the other firm. Thus, period 1 and 2 quantities are strategic complements. Both firms increase their first period outputs, and therefore, they actually lower retained earnings. As illustrated by Fig. 2 expected equity values are decreasing with an increase in leverage.

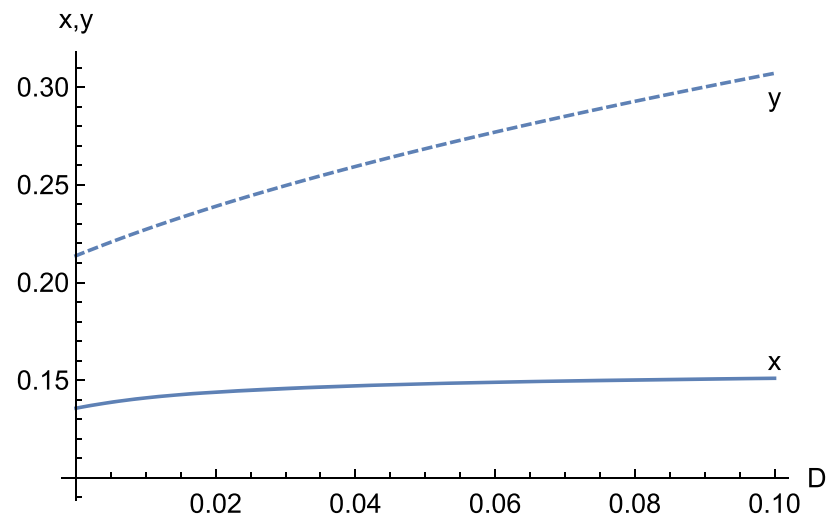

Fig. 1 Output quantities in period 1 (solid line) and period 2 (dashed line) for different levels of debt in the symmetric case 


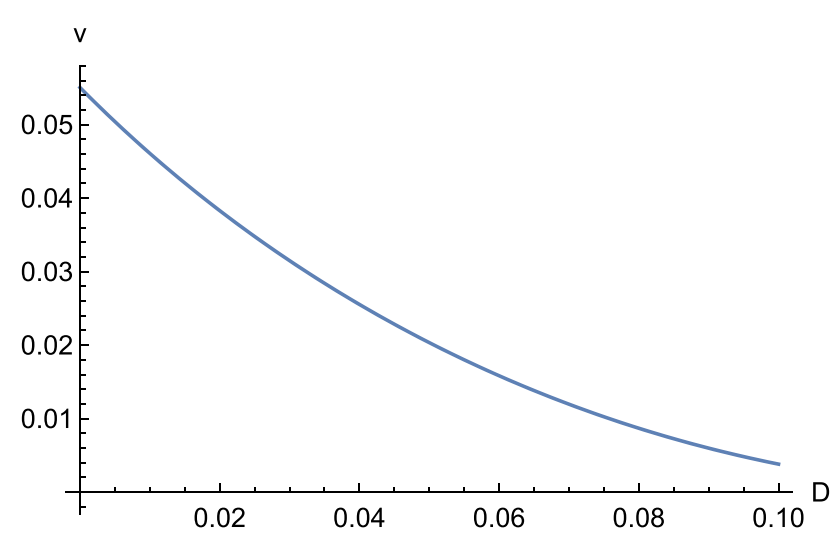

Fig. 2 Expected equity values for different levels of debt in the symmetric case

Proposition 1 clarifies an important point in Glazer's analysis. It is not the nature of debt (long term versus short term) that causes firms to collude in an oligopolistic product market but the way profits are paid out as dividends. This leads us to the next question that we want to address in this paper. So far, we assumed an exogenous dividend policy of the firm by specifying $\alpha_{i}$ ex ante. Now we are interested in deriving an optimal dividend policy. Here we need to remember that optimality refers to the scenario where managers maximize the equity value of the firm. We assume that the decision about debt issuance is fixed prior to the decisions on first period outputs and dividend policy which are selected simultaneously.

Proposition 2 If risk-neutral managers set the dividend policy $\alpha_{i}$ and $\alpha_{j}$ so as to maximize the equity value of the firm, they would pay out first period profits immediately, i.e., choose $\alpha_{i}=\alpha_{j}=0$.

\section{Proof See "Appendix."}

This proposition illustrates the effect of limited liability. Since there is a positive probability of bankruptcy in the second period, the firm has an incentive to distribute all profits from the first period immediately. Retaining part of first period profits for possibly distributing them at the end of the second period would reduce the expected equity value. Further, more retained profits induce a more aggressive rival's output policy and hence smaller second period expected profits. ${ }^{10}$

\section{The Existence of Multiple Equilibria}

After having pointed out the strategic role of dividend payments and debt we want to highlight a second feature of Glazer's model. So far we have primarily looked at the symmetric equilibrium and have ignored the possibility of multiple equilibria. In this section we will present a numerical example that shows the existence of asymmetric equilibria even in the case where the firms have identical fundamentals.

We start out with the case of no debt where all the profits of period 1 are retained $\left(\alpha_{1}=\right.$ $\alpha_{2}=1$ ) and calculate the first period equilibrium quantities. They are graphically depicted in

$\overline{10}$ We are grateful to an anonymous referee for pointing out this argument to us. 


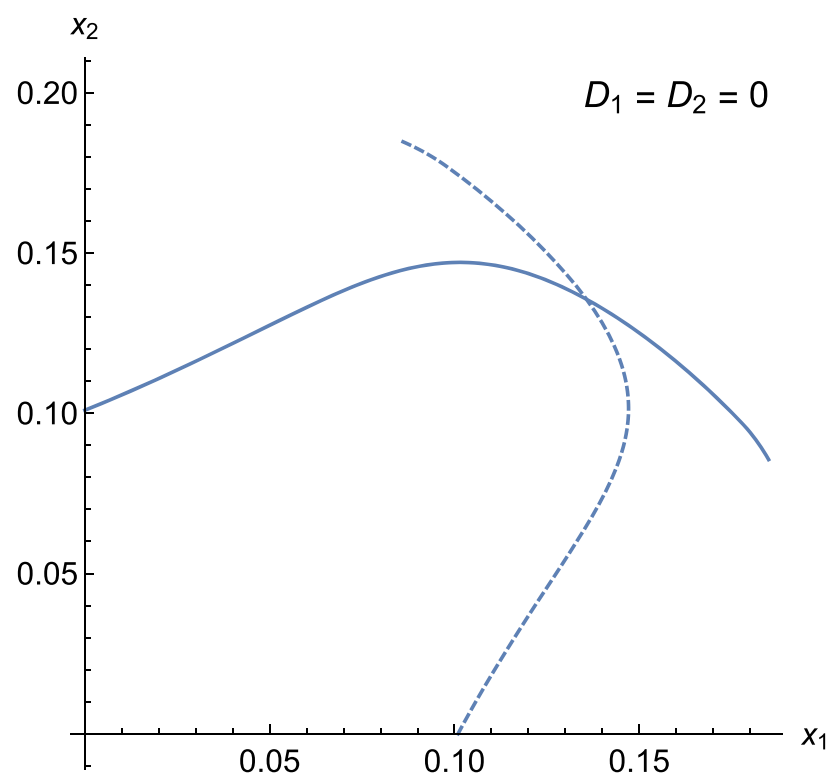

Fig. 3 Reaction functions for firm 1 (solid line) and firm 2 (dashed line) for $D_{1}=D_{2}=0$

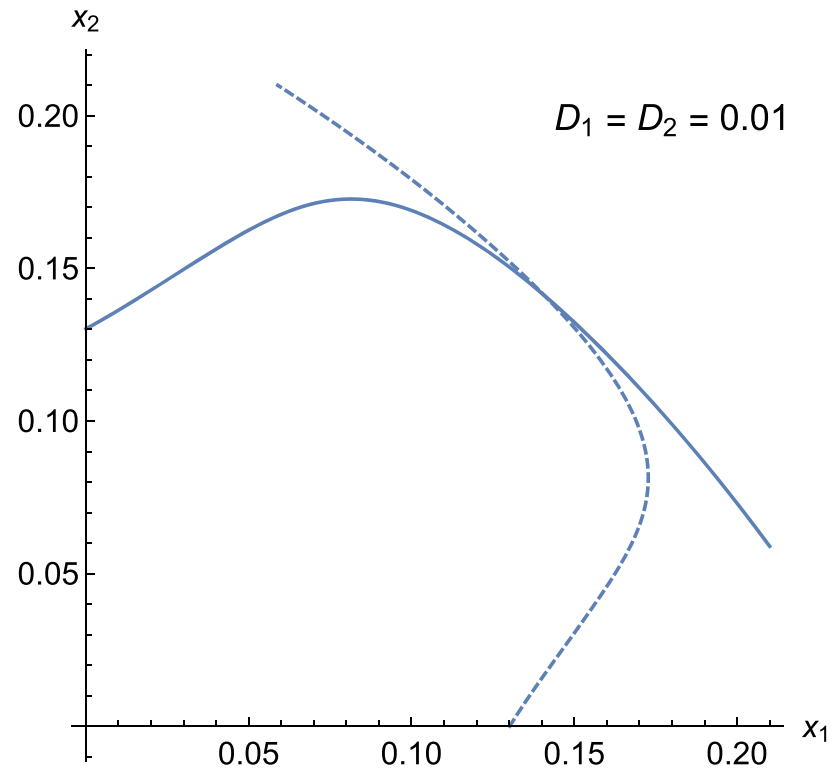

Fig. 4 Reaction functions for firm 1 (solid line) and firm 2 (dashed line) for $D_{1}=D_{2}=0.01$

Fig. 3. In that figure we plot the reaction functions for the two firms. The point of intersection corresponds to the Nash equilibrium. We now increase the level of debt to $D_{1}=D_{2}=D=$ 0.01. In this case the uniqueness of the equilibrium remains (see Fig. 4). As debt is increased further, we get something like a bifurcation, so that at, for example $D=0.016$ the reaction functions intersect three times, implying the existence of three equilibria as shown in Fig. 5. 

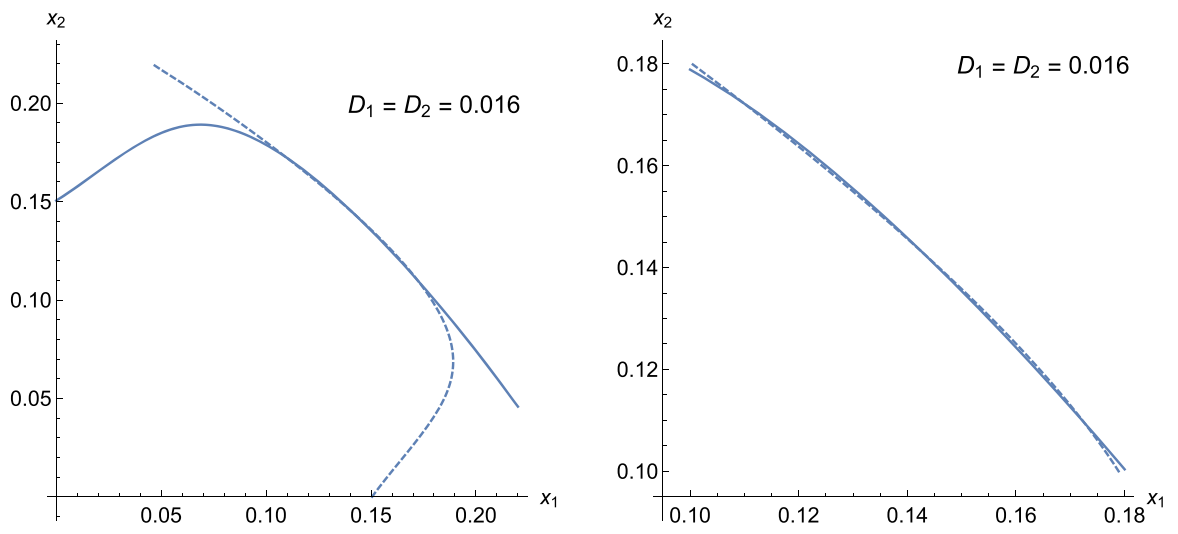

Fig. 5 Reaction functions for firm 1 (solid line) and firm 2 (dashed line) for $D_{1}=D_{2}=0.016$. In the right panel we zoom in on the reaction functions

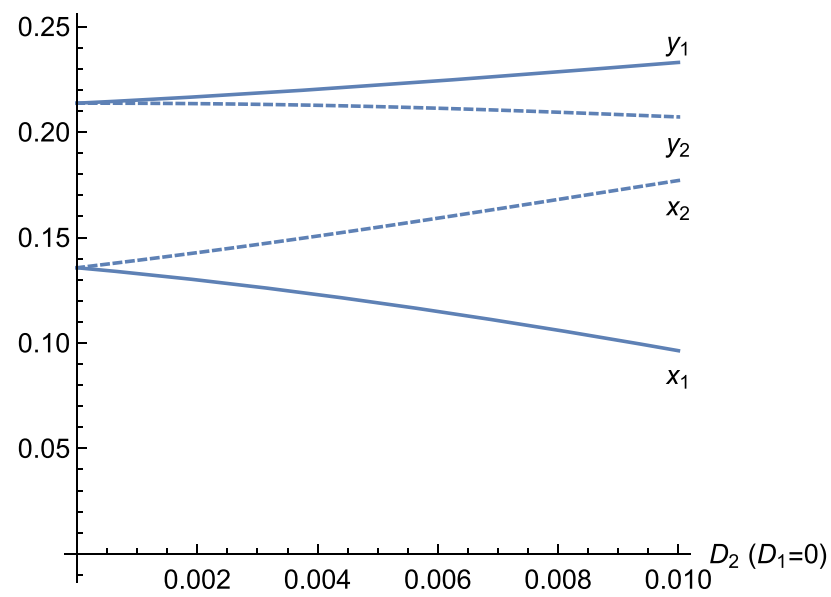

Fig. 6 Output quantities in period $1\left(x_{i}\right)$ and period $2\left(y_{i}\right)$ in the asymmetric case. The debt level of firm 1 (solid lines) is kept constant at $D_{1}=0$, the debt level of firm 2 (dashed lines), $D_{2}$, varies

One of these is symmetric, and the other two are asymmetric. From the graphs in Fig. 5 we see that the symmetric equilibrium is stable, while the two asymmetric ones are unstable. The existence of three equilibria implies that even in the case where firms have identical cost, demand, and capital structures, their output market behavior can differ substantially. When the level of debt is increased further, the multiplicity disappears and uniqueness is restored (as in Fig. 4).

To get some additional insight into the predictions of the model, we also present two asymmetric cases. In one of these, firm 1 is always equity financed, while firm 2 increases debt, and in the other one the debt level of firm one is kept constant at $D=0.016$. In the first case we see that the behavior of the equity financed firm is quite different from the debt financed one (see Figs. 6 and 7), but again equity values of both firms are decreasing with the amount of debt. Figures 8 and 9 present the equilibrium quantities and the equity values for the case in which multiple equilibria exist. 


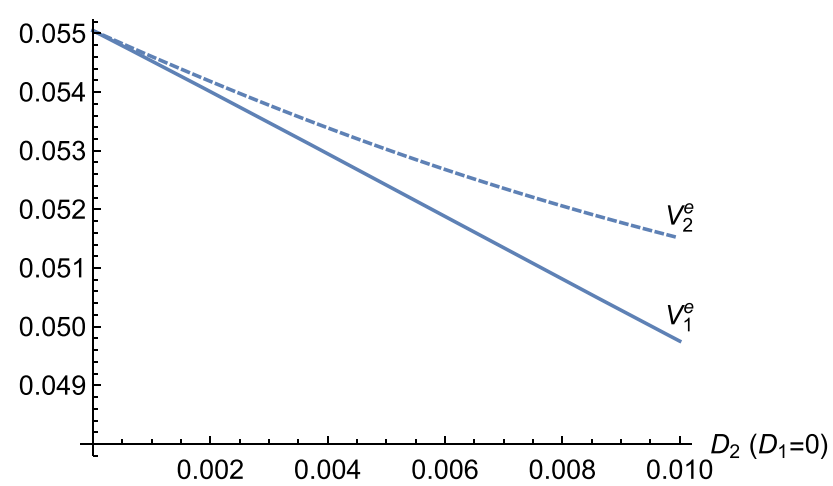

Fig. 7 Expected equity values for the asymmetric case, where the debt level of firm 1 (solid line) is kept constant at $D_{1}=0$, the debt level of firm 2 (dashed line), $D_{2}$, varies

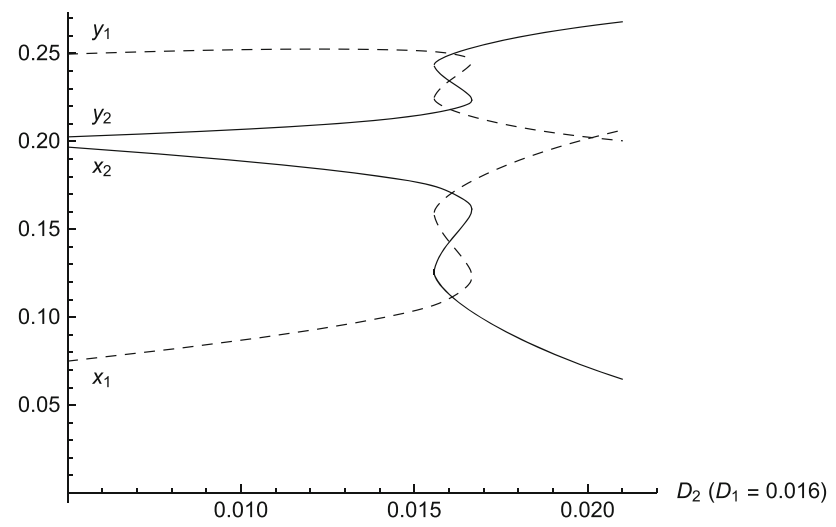

Fig. 8 Output quantities in period $1\left(x_{i}\right)$ and period $2\left(y_{i}\right)$ in the asymmetric case. The debt level of firm 1 (solid lines) is kept constant at $D_{1}=0.016$, the debt level of firm 2 (dashed lines), $D_{2}$, varies

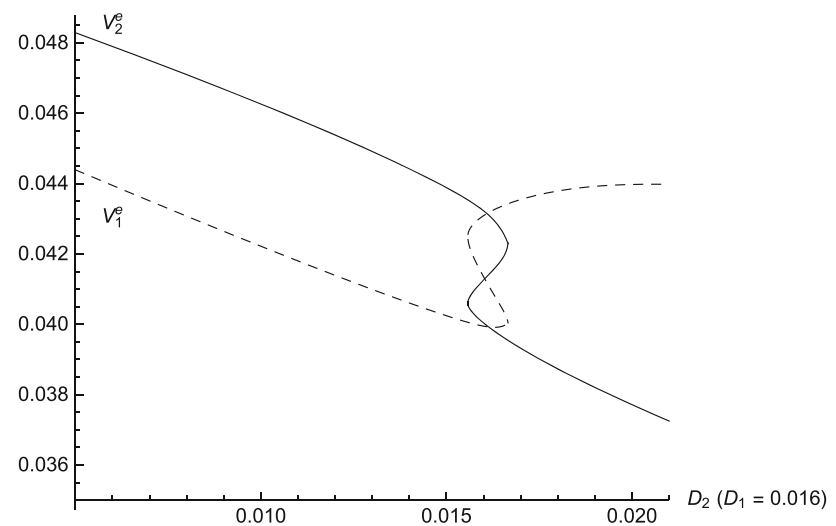

Fig. 9 Expected equity values for the asymmetric case, where the debt level of firm 1 (solid line) is kept constant at $D_{1}=0.016$, the debt level of firm 2 (dashed line), $D_{2}$, varies 


\section{Conclusions}

In this paper we analyze the effects of dividend payments on the product market behavior of firms if markets are oligopolistic and firms issue debt. It turns out that it is not the nature of debt that plays a crucial role for the equilibrium outputs in the two periods but the way profits earned in the first period are distributed to the shareholders. In particular, we show that paying out dividends at the end of the first period causes managers in the case of limited liability and equity value maximization to increase output in both periods. To understand this result, remember that firms have an incentive for collusive behavior in the first period if all first period earnings are carried over to the second period, as was shown already by Glazer [11]. If all first period profits are distributed to shareholders, firms will produce Cournot output since first period profits are irrelevant for the output strategy used in the second period. We show that distributing first period profits immediately is the optimal dividend policy. Furthermore, in our simple model it turns out that higher debt levels cause firms to be pursue more aggressive output strategies in both periods when first period profits are retained.

The results presented here critically depend on a number of assumptions. Firstly, we have assumed that firms are engaged in quantity competition rather than price competition. For the latter, see, for example, Dasgupta and Titman [6] and the empirical support found by Chevalier [5] that debt has an effect on the pricing policy of a firm, as well as Pichler et al. [18] who provide empirical evidence of the limited liability effect. It is to be expected that Bertrand competition would change the incentive for the firms to collude in the first period since prices in the second period are higher in cases where marginal revenue increases with the uncertainty (see also Baldauf et al. [1] for the case of price competition in a model with strategic debt). Secondly, managers are assumed to maximize equity value only. It would be interesting to look at the case where they maximize a combination of both equity and debt value or model the issuance of debt explicitly which might allow also to study the effect of debt on welfare.

Another interesting approach would be the extension to a multi-period interaction. ${ }^{11}$ As the number of periods increases the probability that the firm defaults at some time tends to one. For such an extension indebtedness has to be modeled in more detail. For example, do firms pay back debt as perpetuity or will they repeatedly issue debt? Do conditions for debt issuance have to be renegotiated? Aspects like this provide avenues for future research.

Acknowledgements Open access funding provided by University of Vienna.

Open Access This article is distributed under the terms of the Creative Commons Attribution 4.0 International License (http://creativecommons.org/licenses/by/4.0/), which permits unrestricted use, distribution, and reproduction in any medium, provided you give appropriate credit to the original author(s) and the source, provide a link to the Creative Commons license, and indicate if changes were made.

\footnotetext{
11 An infinite time horizon model addressing interactions between product market competition and investment valuation is Spiegel and Tookes [22]. They study a continuous-time model in a multi firm setting with heterogeneous products where firms compete for share of industry sales by spending funds to acquire each other's customers.
} 


\section{Appendix}

Proof of Proposition 0 The second period corresponds to the situation in Brander and Lewis [3]; thus, the first two statements of the proposition follow from their Proposition 2,

$$
\frac{\mathrm{d} y_{i}^{e}}{\mathrm{~d} R_{j}}>0 \text { and } \frac{\mathrm{d} y_{i}^{e}}{\mathrm{~d} R_{i}}<0 .
$$

These imply that $\frac{\mathrm{d} V_{i}^{e}}{\mathrm{~d} R_{j}}>0$, where

$$
V_{i}^{e}=\left(1-\alpha_{i}\right) \Pi_{i}^{1}\left(x_{i}, x_{j}\right)+\int_{\hat{z}_{i}}^{1}\left(\Pi_{i}^{2}\left(z, y_{i}^{e}, y_{j}^{e}\right)+R_{i}\left(x_{i}, x_{j}, \alpha_{i}, D_{i}\right)\right) \mathrm{d} F(z)
$$

since $\frac{\partial \Pi_{i}^{2}}{\partial y_{j}}>0$ and $\frac{\partial^{2} \Pi_{i}^{2}}{\partial y_{i} \partial z}>0$, as argued by Glazer [11], Corollary 0 .

It remains to be shown that $\frac{\mathrm{d} V_{i}^{2, e}}{\mathrm{~d} R_{i}}>0$. Thus, we derive the first-order condition of the maximum problem $(7)+(8)$. Note that

$$
\begin{aligned}
\int_{\hat{z}_{i}}^{1}\left(\Pi_{i}^{2}\left(z, y_{i}, y_{j}\right)+R_{i}\left(x_{i}, x_{j}, \alpha_{i}, D_{i}\right)\right) \mathrm{d} F(z) & =\int_{\hat{z}_{i}}^{1}\left(\Pi_{i}^{2}\left(z, y_{i}, y_{j}\right)-\Pi_{i}^{2}\left(\hat{z}, y_{i}, y_{j}\right)\right) \mathrm{d} z \\
& =\int_{\hat{z}_{i}}^{1}\left(z y_{i}-\hat{z}_{i} y_{i}\right) \mathrm{d} z=\frac{1}{2}\left(1-\hat{z}_{i}\right)^{2} y_{i}
\end{aligned}
$$

where we have used the fact that $z$ is uniformly distributed over $[0,1]$. Therefore,

$$
\frac{\partial V_{i}}{\partial y_{i}}=\left(1-\hat{z}_{i}\right)\left(-\frac{\partial \hat{z}_{i}}{\partial y_{i}} y_{i}+\frac{1}{2}\left(1-\hat{z}_{i}\right)\right)
$$

which is $=0$ iff the expression in the bracket is zero. From $\hat{z}_{i}=-\frac{R_{i}}{y_{i}}+y_{i}+y_{j}$ we get the first-order condition

$$
-\frac{R_{i}}{y_{i}}-y_{i}+\frac{1}{2}\left(1+\frac{R_{i}}{y_{i}}-y_{i}-y_{j}\right)=0 \Leftrightarrow y_{i}\left(3 y_{i}+y_{j}-1\right)=-R_{i} .
$$

Expected second period profits are given by

$$
V_{i}^{2, e}=\int_{\hat{z}_{i}}^{1}\left(\Pi_{i}^{2}\left(z, y_{i}^{e}, y_{j}^{e}\right)+R_{i}\left(x_{i}, x_{j}, \alpha_{i}, D_{i}\right)\right) \mathrm{d} F(z)
$$

Differentiating this expression we obtain

$$
\frac{\mathrm{d} V_{i}^{2, e}}{\mathrm{~d} R_{i}}=\int_{\hat{z}_{i}}^{1}(\underbrace{\frac{\partial \Pi_{i}^{2}}{\partial y_{j}} \cdot \frac{\mathrm{d} y_{j}^{e}}{\mathrm{~d} R_{i}}}_{<0}+1) \mathrm{d} F(z)<1-F\left(\hat{z}_{i}\right) .
$$

To prove that the above derivative is $>0$, we totally differentiate the first-order condition (A.1) to get

$$
\left(6 y_{i}+y_{j}-1\right) \mathrm{d} y_{i}+y_{i} \mathrm{~d} y_{j}=-\mathrm{d} R_{i} .
$$




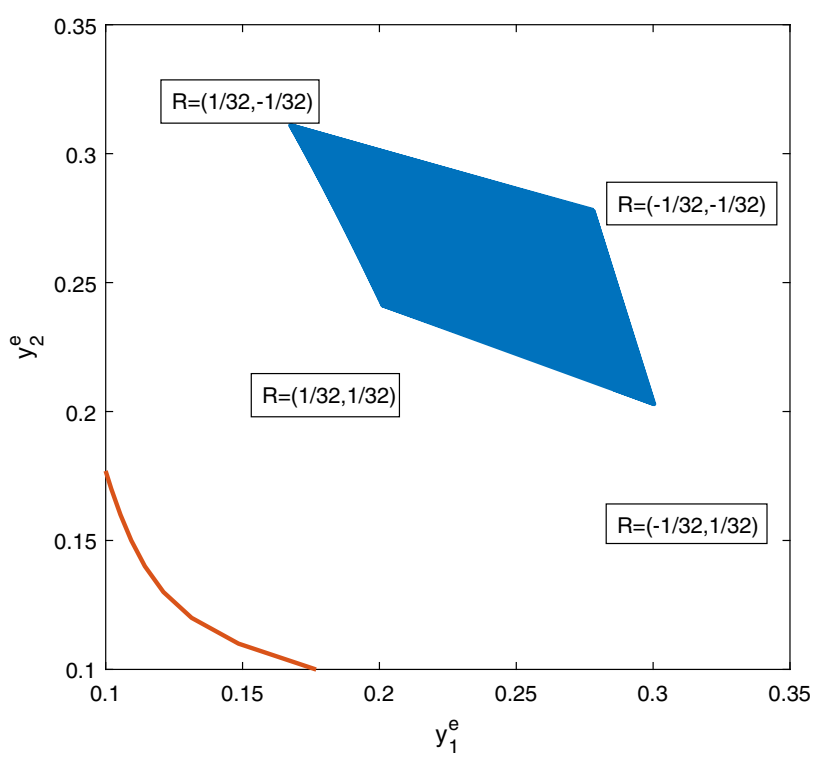

Fig. 10 The shaded region $\left\{\left(y_{1}, y_{2}\right): y_{1}\left(3 y_{1}+y_{2}-1\right)=-R_{1}, y_{2}\left(3 y_{2}+y_{1}-1\right)=-R_{2},-\frac{1}{32} \leq\right.$ $\left.R_{1}, R_{2} \leq \frac{1}{32}\right\}$ represents all combinations $y_{1}, y_{2}$ which fulfill the first-order conditions (A.1). The curve represents $\left(6 y_{1}+y_{2}-1\right)\left(6 y_{2}+y_{1}-1\right)-2 y_{1} y_{2}=0$, in the area above the curve this expression is positive, i.e., for all points in the shaded region the nominator in (A.2) is positive

Together with the condition $\mathrm{d} R_{j}=0$ this yields

$$
\begin{aligned}
& \frac{\mathrm{d} y_{i}^{e}}{\mathrm{~d} R_{i}}=-\frac{6 y_{j}+y_{i}-1}{\left(6 y_{i}+y_{j}-1\right)\left(6 y_{j}+y_{i}-1\right)-y_{i} y_{j}}<0 \\
& \frac{\mathrm{d} y_{j}^{e}}{\mathrm{~d} R_{i}}=\frac{y_{j}}{\left(6 y_{i}+y_{j}-1\right)\left(6 y_{j}+y_{i}-1\right)-y_{i} y_{j}}>0 .
\end{aligned}
$$

where the signs follow from the results above. Thus,

$$
\frac{\mathrm{d} V_{i}^{2, e}}{\mathrm{~d} R_{i}}=(1-F(\hat{z})) \frac{\left(6 y_{i}+y_{j}-1\right)\left(6 y_{j}+y_{i}-1\right)-2 y_{i} y_{j}}{\left(6 y_{i}+y_{j}-1\right)\left(6 y_{j}+y_{i}-1\right)-y_{i} y_{j}} .
$$

Since $1-F\left(\hat{z}_{i}\right)>0$ and the denominator in the above equation is positive the sign of $\frac{\mathrm{d} V_{i}^{e}}{\mathrm{~d} R_{i}}$ is determined by the nominator.

We assume that retained profits of both firms lie in the interval $\left[-\frac{1}{32}, \frac{1}{32}\right]$. Figure 10 shows that all second period equilibrium outputs lie in the region where $\left(6 y_{i}+y_{j}-1\right)\left(6 y_{j}+y_{i}-\right.$ 1) $-2 y_{i} y_{j}>0$.

Proof of Lemma 1 The first-order condition for optimal $x_{i}$, given $\alpha_{i}$ and $\alpha_{j}$ leads to

$$
\begin{aligned}
\frac{\partial V_{i}^{e}}{\partial x_{i}}= & \left(1-\alpha_{i}\right) \frac{\partial \Pi_{i}^{1}}{\partial x_{i}}+\int_{\hat{z}_{i}}^{1} \alpha_{i}\left(\frac{\partial \Pi_{i}^{2}}{\partial y_{j}} \cdot \frac{\partial y_{j}^{e}}{\partial R_{i}}+1\right) \frac{\partial \Pi_{i}^{1}}{\partial x_{i}} \mathrm{~d} F(z) \\
& +\int_{\hat{z}_{i}}^{1} \alpha_{j} \frac{\partial \Pi_{i}^{2}}{\partial y_{j}} \cdot \frac{\partial y_{j}^{e}}{\partial R_{j}} \cdot \frac{\partial \Pi_{i}^{1}}{\partial x_{i}} \mathrm{~d} F(z)
\end{aligned}
$$




$$
=\frac{\partial \Pi_{i}^{1}}{\partial x_{i}} \underbrace{\left(1-\alpha_{i}+\alpha_{i} \frac{\partial V_{i}^{2, e}}{\partial R_{i}}\right)}_{>0}+\alpha_{j} \underbrace{\frac{\partial \Pi_{j}^{1}}{\partial x_{i}} \cdot \frac{\partial V_{i}^{2, e}}{\partial R_{j}}}_{<0}=0 .
$$

Hence, $\frac{\partial \Pi_{i}^{1}}{\partial x_{i}}>0$. This implies that firm $i$ could increase first period profits by increasing its output. Therefore, the optimal output must be less than Cournot output.

Proof of Proposition 2 We differentiate $V_{i}^{e}$ with respect to $\alpha_{i}$. Note that first period otuputs are decided simultaneously to the level of dividend payouts and after debt levels have been fixed.

$$
\begin{aligned}
\frac{\partial V_{i}^{e}}{\partial \alpha_{i}} & =-\Pi_{i}^{1}\left(x_{i}, x_{j}\right)+\int_{\hat{z}_{i}}^{1}\left(\frac{\partial \Pi_{i}^{2}}{\partial y_{j}} \cdot \frac{\partial y_{j}^{e}}{\partial R_{i}} \cdot \frac{\partial R_{i}^{1}}{\partial \alpha_{i}}+\Pi_{i}^{1}\left(x_{i}, x_{j}\right)\right) \mathrm{d} F(z) \\
& =-\Pi_{i}^{1}\left(x_{i}, x_{j}\right)+\Pi_{i}^{1}\left(x_{i}, x_{j}\right) \underbrace{\int_{1}^{1}\left(\frac{\partial \Pi_{i}^{2}}{\partial y_{j}} \cdot \frac{\partial y_{j}^{e}}{\partial R_{i}}+1\right) \mathrm{d} F(z)}_{\hat{z}_{i}} \\
& \leq-F\left(\hat{z}_{i}\right) \Pi_{i}^{1}\left(x_{i}, x_{j}\right) \leq 0 .
\end{aligned}
$$

Hence, $V_{i}^{e}$ obtains its maximum at $\alpha_{i}=0$.

\section{References}

1. Baldauf A, Dockner EJ, Reisinger H (2000) The effects of debt on prices in oligopolistic new product markets. J Bus Res 50:201-207

2. Bolton P, Scharfstein D (1990) A theory of predation based on agency problems in financial contracting. Am Econ Rev 80:93-106

3. Brander JA, Lewis TR (1986) Oligopoly and financial structure: the limited liability effect. Am Econ Rev 76:956-970

4. Campello M (2006) Debt financing: does it boost or hurt firm performance in product markets? J Financ Econ 82:135-172

5. Chevalier JA (1995) Do LBO supermarkets charge more? An empirical analysis of the effects of LBO's on supermarket pricing. J Finance 50:1095-1112

6. Dasgupta S, Titman S (1998) Pricing strategy and financial policy. Rev Financ Stud 11:705-737

7. Dimitrov V (2011) Capital structure and firm risk. In: Baker HK, Martin GS (eds) Capital structure and corporate financing decisions: theory, evidence, and practice. Wiley, Hoboken, pp 59-73

8. Faure-Grimaud A (2000) Product market competition and optimal debt contracts: the limited liability effect revisited. Eur Econ Rev 44:1823-1840

9. Frésard L (2010) Financial strength and product market behavior: the real effects of corporate cash holdings. J Finance 65:1097-1122

10. Fulghieri P, Nagarajan S (1992) Financial contracts as lasting commitments: the case of a leveraged oligopoly. J Financ Intermed 2:2-32

11. Glazer J (1994) The strategic effects of long-term debt in imperfect competition. J Econ Theory 62:428443

12. Hadlock CJ, Sonti R (2012) Financial strength and product market competition: evidence from asbestos litigation. J Financ Quant Anal 47:179-211

13. Harris M, Raviv A (1991) The theory of capital structure. J Finance 46:297-355

14. Maksimovic V (1988) Optimal capital structure in repeated oligopolies. Rand J Econ 19:389-407

15. Maksimovic V (1995) Financial structure and product market competition. In: Jarrow RA, Maksimovic V, Ziemba WT (eds) Handbooks in operations research and management science finance, vol. 9. pp 887-920 
16. Parsons C, Titman S (2007) Capital structure and corporate strategy. In: Eckbo BE (ed), Handbook of corporate finance: empirical corporate finance, vol. 2. pp 203-234

17. Phillips GM (1995) Increased debt and industry product markets an empirical analysis. J Financ Econ 37:189-238

18. Pichler P, Stomper A, Zulehner C (2008) Why leverage affects pricing. Rev Financ Stud 21:1733-1765

19. Showalter D (1995) Oligopoly and financial structure, comment. Am Econ Rev 85:647-653

20. Showalter D (1999) Debt as an entry deterrent under Bertrand price competition. Can J Econ 32:10691081

21. Smith DJ, Chen J, Anderson HD (2012) The relationship between capital structure and product markets: evidence from New Zealand. Rev Quant Financ Acc 38:1-24

22. Spiegel M, Tookes H (2013) Dynamic competition, valuation, and merger activity. J Finance 68:125-172 